\title{
Review Article \\ Role of Passive Safety Systems in Chinese Nuclear Power Development
}

\author{
X. Cheng, ${ }^{1}$ Y. H. Yang, ${ }^{1}$ Y. Ouyang, ${ }^{2}$ and H. X. Miao ${ }^{2}$ \\ ${ }^{1}$ School of Nuclear Science and Engineering, Shanghai Jiao Tong University, Dongchuan Road 800, Shanghai 200240, China \\ ${ }^{2}$ Experts Committee, State Nuclear Power Technology Cooperation, 17 Financial Street, Xicheng District, Beijing 100032, China
}

Correspondence should be addressed to X. Cheng, chengxu@sjtu.edu.cn

Received 14 November 2008; Accepted 9 April 2009

Recommended by Dino A. Araneo

Passive safety systems have been widely applied to advanced water-cooled reactors, to enhance the safety of nuclear power plants. The ambitious program of the nuclear power development in China requires reactor concepts with high safety level. For the near-term and medium-term, the Chinese government decided for advanced pressurized water reactors with an extensive usage of passive safety systems. This paper describes some important criteria and the development program of the Chinese large-scale pressurized water reactors. An overview on representative research activities and results achieved so far on passive safety systems in various institutions is presented.

Copyright (C) 2009 X. Cheng et al. This is an open access article distributed under the Creative Commons Attribution License, which permits unrestricted use, distribution, and reproduction in any medium, provided the original work is properly cited.

\section{Introduction}

The operating experience of more than five decades civil utilization of nuclear energy shows significant advantages of nuclear power with respect to environment protection, economic competitiveness, and power supply stability. Nowadays nuclear power produces about $16 \%$ of the total electricity worldwide. The complicated and unstable situation of the international relationship and the rapidly growing energy demand force the international community to reassess the role of nuclear power.

Since the start of the economic reform in the 1970s, the Chinese economics has been undergoing rapid development. One of the bottlenecking issues in the Chinese economics development is a sustainable and environment friendly energy supply. By the middle of this century the primary energy demand in China will be four times as that of today. For the time being, more than $70 \%$ of the primary energy comes from fossil fuel. A higher portion (about $80 \%$ ) is found in the electricity production. Development of environment friendly energy supplies becomes thus a crucial issue in the future Chinese economy. Due to the wellknown limitation in renewable energy and hydro-power, nuclear power is considered as a safe, clean, sustainable and economic energy source.
In November 2007, China issued an ambitious program of mid-term nuclear power development [1]. The total nuclear power installation will reach $40 \mathrm{GW}$ or higher by 2020. According to the estimation of the Chinese nuclear experts, the nuclear power installation will be around 250 GW by the middle of this century. That is about $15 \%$ of the total electricity production at that time. Figure 1 shows schematically the expected nuclear power development in China.

From the technology point of view, the development of nuclear power technology worldwide has undergone four generations. To the first generation belong mainly the demonstration plants of small power capacity. Based on the experience gathered from the first generation, many standardized concepts of nuclear power plants (NPPs) were proposed and the second generation of NPP was born. The most nuclear power plants operating nowadays belong to the second generation. After the accidents of TMI and Chernobyl intensive efforts were made to improve the safety features of the second generation NPP, and the third generation of nuclear power technology was developed. Compared to the second generation, the third generation owns a much higher safety level. The core damage frequency (CDF) is lower than $10^{-5}$ per reactor-year. It is expected that in the next 2-3 


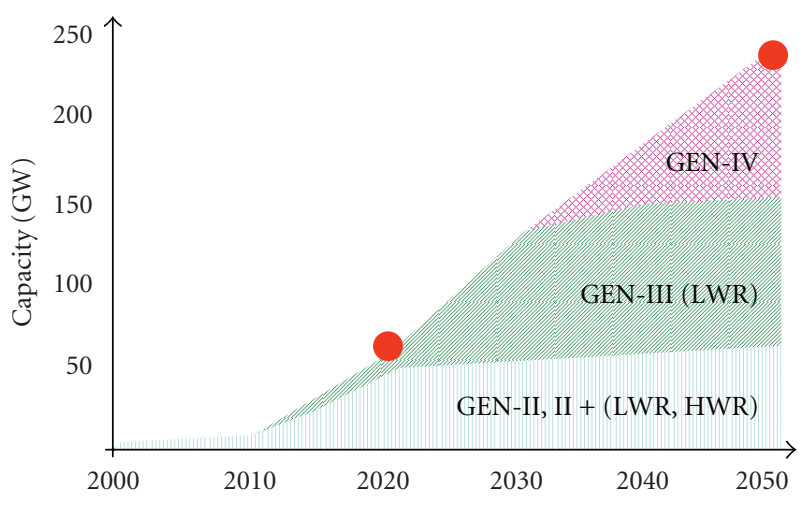

FIGURE 1: Expected nuclear power development in China.

decades, the new constructed NPP use mainly reactors of generation III (GEN-III).

Various types of GEN-III pressurized water reactors (PWR) are now available. Two of the most representative ones are AP1000 of Westinghouse [2] and EPR of AVERA [3]. One of the common features of the GEN-III reactors is their enhanced safety performance. This is achieved using different approaches, from the improvement of human reliability to the introduction of completely new subsystems. Passive safety systems are widely applied, especially in the AP1000 concept of Westinghouse. Passive safety systems are recommended to be applied wherever it is feasible.

As shown in Figure 1, water-cooled reactors of GEN-II or GEN-II extension will make the major contribution to the nuclear power generation until 2020. After then light water reactors (LWRs) of GEN-III will start to be built in large scale. This paper discusses the state of the art and the future development of the technology lines of Chinese NPP. Emphasis will be put on the application of passive safety systems. A brief overview of research activities on passive safety systems is given.

\section{Chinese Nuclear Power Technology}

Based on the experiences gathered worldwide in the nuclear power development of the past five decades, attention has to be paid to the following issues, to ensure a safe, economic, and fast development of nuclear power:

(i) selection of technology lines;

(ii) realization of self-reliance technology;

(iii) nationwide coordination.

2.1. Selection of Technology Lines. It is well agreed that realization of the ambitious nuclear power program requires urgently the decision of the technology lines for the future nuclear power plants. At present 11 units are under operation with a total installed capacity of $9 \mathrm{GW}$, and 12 units are now under construction with an installed capacity of $12 \mathrm{GW}$. There are additional 18 units; which construction will start in the next three years. All of these NPP units consist of watercooled reactors. Therefore, water-cooled reactors have clearly been selected as the main reactor type for the next decades.

The operating NPP units are from four different technology lines, that is, the Chinese PWR of $300 \mathrm{MW} / 600 \mathrm{MW}$ class, the Canadian CANDU of $700 \mathrm{MW}$, the French PWR of $900 \mathrm{MW}$, and the Russian WWER of $1000 \mathrm{MW}$. The existing experience emphasizes the necessity to reduce the number of technology lines for the future NPP. It is highly desired to define a single major technology line for the future Chinese nuclear power generation. Considering the Chinese specific situation and the experience gathered in the national and international nuclear community, it is well agreed and decided that water-cooled reactors of GEN-III will be the main reactor type for the future Chinese nuclear power generation, at least for the mid-term. Passive safety systems should be key features of the Chinese GEN-III PWR. In addition it should fulfill the following requirements:

(i) system simplicity;

(ii) economical competitiveness;

(iii) operating reliability and easy maintainability;

(iv) advanced passive engineering safety features;

(v) compliment with the latest safety codes for severe accident prevention and mitigation measures issued by China National Nuclear Safety Administration (NNSA) and IAEA;

(vi) digital instrumentation and control system;

(vii) advanced human factor engineering technique and advanced main control room.

The above technology requirements justify the choice of AP1000 technology of Westinghouse as the reference technology for the Chinese GEN-III PWR.

2.2. Self-Reliance Technology. As soon as the future technology lines are defined, extensive efforts should be made to develop self-reliance technology, so as to reduce the strong technology dependence on other countries, as it is at the present stage. To achieve the mid-term target, China issues twofold strategy. In one side construction of NPPs based on existing GEN-II PWR technology will be continued. Minor modification of the GEN-II PWR power plants will be undertaken with respect to reactor fuel management and safety performance. The improved GEN-II PWR power plants make the main contribution to the newly installed nuclear power plants in the next 10 years. Most of the NPPs nowadays under construction or receiving the construction license do belong to this category, for example, Qinshan Phase-II extension which bases on Chinese PWR technology of $600 \mathrm{MW}$ class and CPR (improved reactor type based on French M310).

In the other side large efforts are made to accelerate the self-reliance process of the GEN-III PWR technology. The Chinese government has issued a large national program to develop technology of advanced large-scale pressurized water reactors [4] and to accelerate the self-reliance of the 
Chinese nuclear technology. The Nuclear Power Self-reliance Program has been launched with Sanmen project in Zhejiang Province and Haiyang project in Shandong Province as supporting projects [5]. Three steps will be taken for the development of the "Chinese large-scale advanced PWR nuclear power plant.”

(i) Transfer of AP1000 technology. In this stage, design and construction of 4 units AP1000 will take place under the guidance of Westinghouse. Chinese engineers and scientists will actively participate in this procedure.

(ii) Design of modified AP1000 NPP. Based on the experience gathered in the first stage, the existing AP1000 will be modified. This work will be carried out by Chinese engineers and scientists in collaboration with Westinghouse.

(iii) Design and construction of self-reliance large-scale PWR. The Chinese AP1000 will be extended with respect to enlarging reactor power (larger than $1400 \mathrm{MW}$ ) and improving economics. At the end of this stage (2020) a prototype reactor of the Chinese self-reliance GEN-III PWR will be constructed and put into operation.

2.3. Nationwide Coordination. Realization of the self-reliance of nuclear technology requires a high-quality coordination, including various institutions for design, research, manufacture, and education. For this purpose a new organization, the State Nuclear Power Technology Corp. LTD (SNPTC), was founded in 2007. SNPTC is responsible for the self-reliance of the Chinese GEN-III PWR technology and has established subcompanies for research, design, and manufacture, respectively. In addition, SNPTC is also the direct partner for Westinghouse related to the AP1000 technology transfer. The Contracts between SNPTC and Westinghouse signed on July 2007 came into force in September 2007. Four AP1000 units will be put into commercial operation from 2013 to 2015, respectively.

\section{Research Activities on Passive Safety Systems}

Passive safety systems for advanced PWR have achieved significant interests of Chinese nuclear community since 1980s [6]. Since that time China National Nuclear Corporation (CNNC) was developing an advanced Chinese PWR of $600 \mathrm{MW}$ (AC600). The basic philosophy of AC600 is similar to that of AP600 of Westinghouse and equipped with sophisticated passive safety systems. Extensive R\&D activities were carried out, especially at the Nuclear Power Institute of China (NPIC).

Studies on passive safety systems were also carried out with respect to small power water-cooled reactors. A lowtemperature, integral type PWR is proposed by NPIC, as indicated in Figure 2, which utilizes passive systems for safety injection decay heat removal and containment pressure suppression [7]. The reactor thermal power is $250 \mathrm{MW}$. The
TABLE 1

\begin{tabular}{ll}
\hline Total height: & $23 \mathrm{~m}$ \\
Volume scale: & $1 / 395$ \\
Design pressure: & $8.6 \mathrm{MPa}$ \\
Design temperature: & $316 \mathrm{C}$ \\
Heating power: & $500 \mathrm{~kW}$ \\
\hline
\end{tabular}

primary loop has an operating pressure of $2.2 \mathrm{MPa}$ and temperature of $158^{\circ} \mathrm{C} / 199^{\circ} \mathrm{C}$.

At the Institute of Nuclear and New Energy Technology (INET) of the Qinghua University, another type of small power integral water-cooled reactor design is proposed [8]. The reactor system is similar to that of the International Reactor Innovative and Secure (IRIS, [9]). No pumps are required for both normal and abnormal operating conditions. Two passive safety systems are applied, that is, passive decay heat removal and passive boron injection.

Recently, with the decision on the technology line for the Chinese GEN-III PWR passive safety systems attract again the major attention and interests of the Chinese nuclear community. R\&D activities were initiated at various research institutions. The International Workshop on Passive Safety Systems in Advanced PWRs took place in Shanghai in April 2008, to provide a platform for the international nuclear community to exchange research results and design experience on the passive safety systems applied to advanced PWRs, to enhance the contact and collaboration between the Chinese research institutions and international partners, and to give the Chinese nuclear community and Chinese government authorities an insight into the actual research and design status and future research needs in the passive safety system of advanced PWRs.

In the frame of the AP1000 technology transfer, analysis of the performance of AP1000 passive safety systems has been carried out at various institutions such as Shanghai Nuclear Engineering Research and Design Institute (SNERDI) [10] and the Shanghai Jiao Tong University [11]. In addition, both experimental and numerical investigations were carried out at NPIC on the performance of passive safety systems proposed for large-scale PWR. Figure 3 shows schematically the experimental facility constructed at NPIC for passive decay heat removal systems of advanced Chinese PWR. Some technical specifications are shown in Table 1.

3.1. Passive Containment Safety Systems. As the last safety barrier containment integrity has achieved strong attention of the Chinese nuclear community. Passive containment safety systems were widely applied to advanced water-cooled reactors [13]. As a long-term passive decay heat removal AP1000 uses the natural convection of air combined with thermal radiation in the annuli between both containment shells. For the short-term (the first 72 hours) additional water-film evaporation heat transfer will be provided [2].

To investigate the cooling capability of this passive system and the involved microscopic mechanisms, both experimental and numerical studies are carried out at Shanghai Jiao 


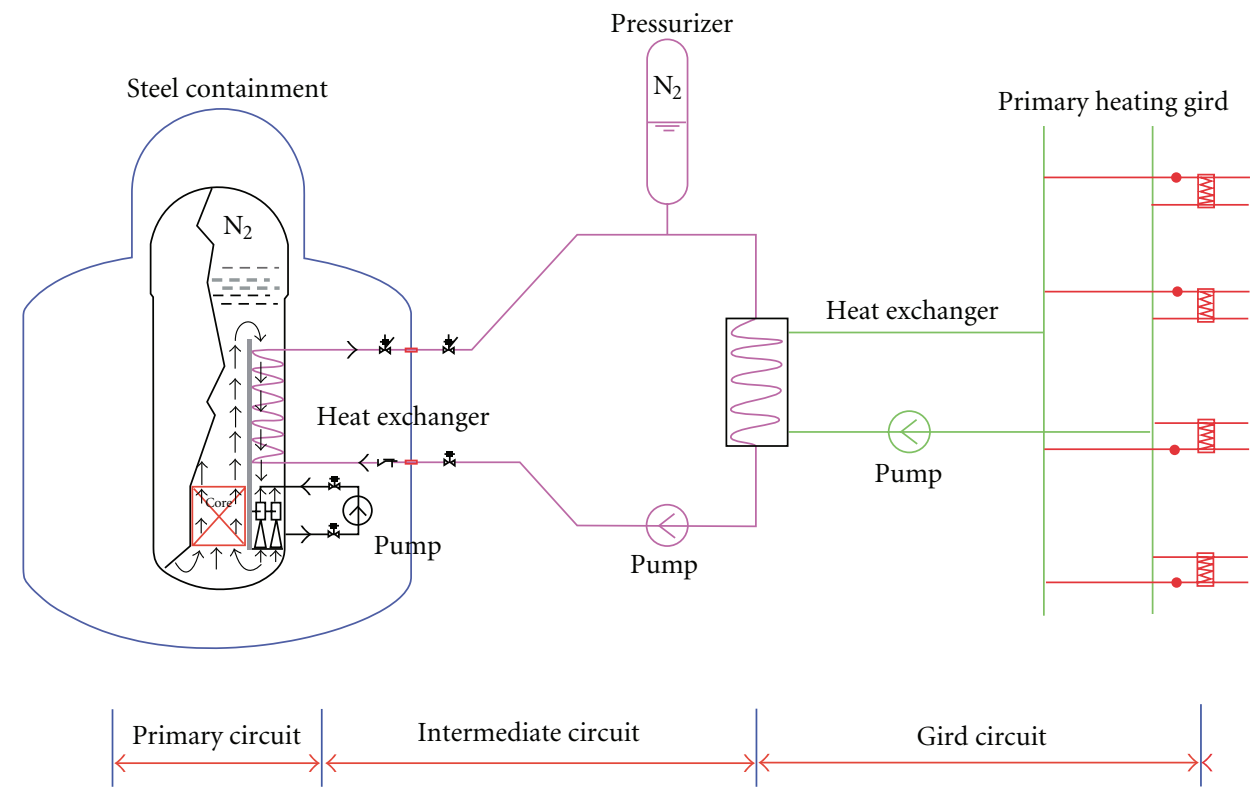

FIgURE 2: Low temperature, integral PWR proposed by NPIC [7].

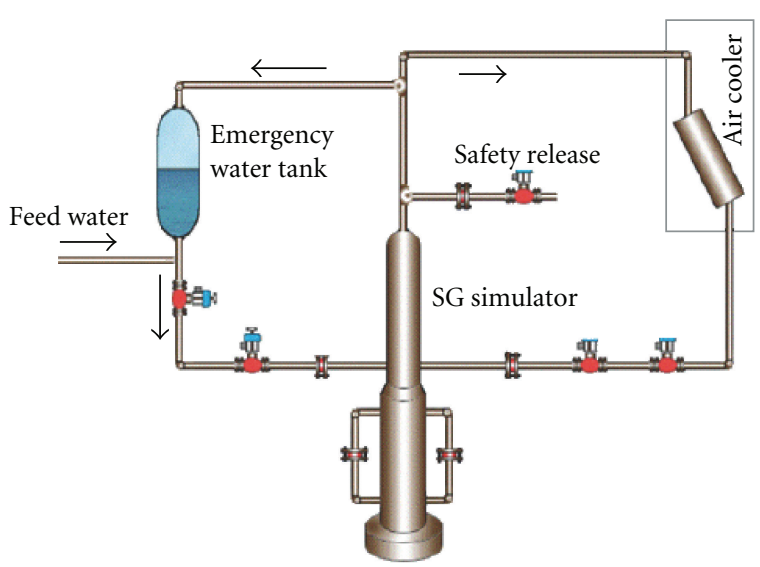

Figure 3: Decay heat removal test facility at NPIC [12].

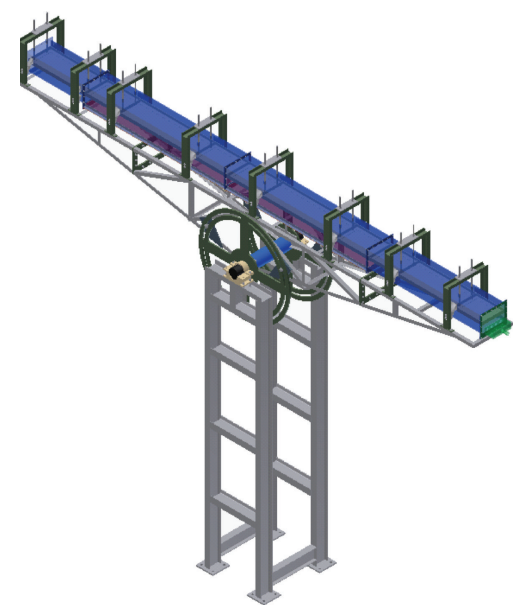

FIgUre 4: Test facility MICARE.
Tong University. Figure 4 shows the test section MICARE, which is a square flow channel with the maximum crosssection of $400 \mathrm{~mm} \times 250 \mathrm{~mm}$. One side of the channel is electrically heated. The heated wall consists of 16 heating plates, which are separately heated to achieve a well uniform distribution of the heated wall temperature. The orientation of the flow channel can be changed arbitrarily. The test section has a total height of $8 \mathrm{~m}$, of which $6 \mathrm{~m}$ (in the middle) can be heated. The test section can be connected to an auxiliary equipment to realize a forced flow of air into the test channel using a compressor.

The heating power of each heated plate is separately controlled, to achieve a uniform wall temperature distribution. The wall temperature can be varied up to $200^{\circ} \mathrm{C}$. The test facility is equipped among others with a large number of thermocouples to measure the distribution of wall temperatures. Hot-wire anemometer and thermocouples are applied to measure the air velocity and air temperature distribution in the flow channel. Calibrations were performed to determine the heat loss from the heated wall to the ambient surroundings at different values of the heated wall temperature.

In addition to the experimental work, numerical simulation is carried out, to understand the microscopic phenomena involved in the mixed convection in a square channel with various orientation. Figure 5 shows an example of numerical results, presenting the heated wall surface temperature along the middle line in the flow direction. The numerical results are obtained with CFD code using various low Reynolds number $k$-epsilon models. As seen, the selection of turbulence models affects strongly the numerical simulation. 


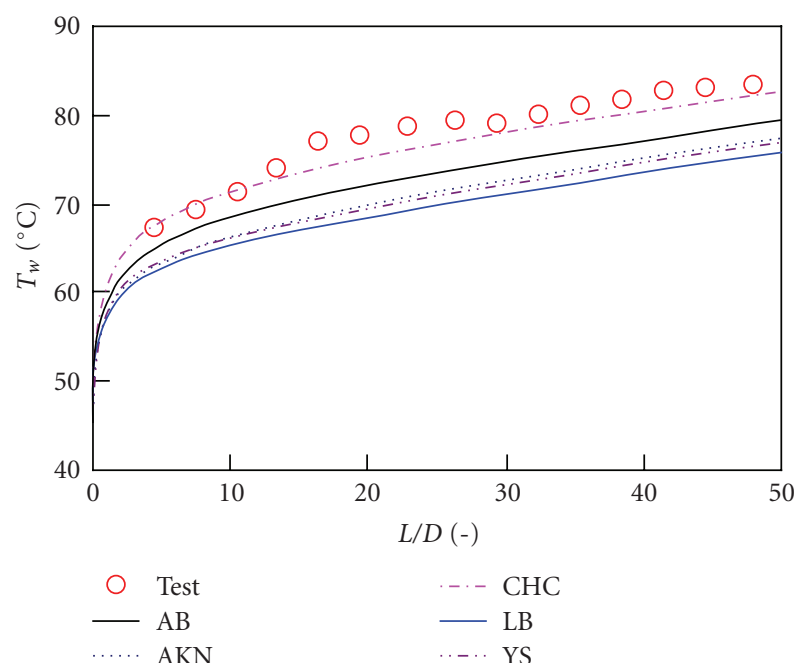

FIGURE 5: Comparison of numerical results with experimental data. AB: model of Abid; AKN: model of Abe/Kondoh/Nagano; CHC: model of Chang/Hsieh/Chen; LB: model of Lam/Bremhost; YS: model of Yang/Shih.

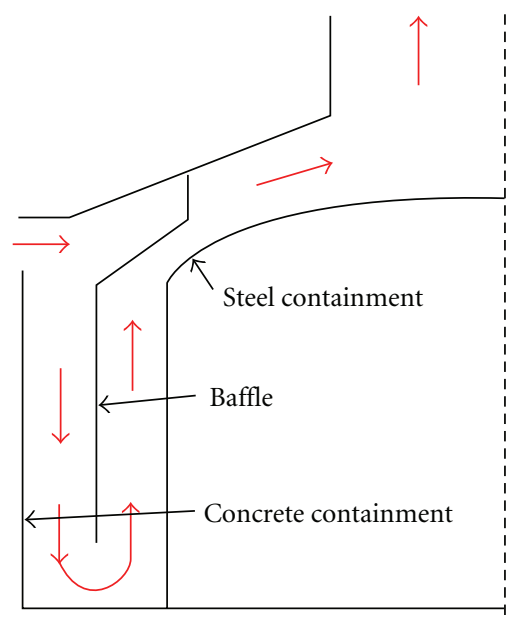

FIGURE 6: Containment model for lumped parameter analysis $[x]$.

To assess the heat removal capability of AP1000 passive containment cooling system, simplified analysis using lumped parameter approach is carried out at SJTU [14]. The lumped parameter model is illustrated in Figure 6. Effects of various parameters on the heat removal capability are investigated. Figure 7 gives an example indicating the effect of the thermal conductivity of the buffer plate on heat removal. Results are obtained with a containment temperature of $150^{\circ} \mathrm{C}$ and the wall emissivity 1 . It is seen that a higher thermal conductivity leads to an increase in heat removal of about $15 \%$. A strong effect is observed in the region of low thermal conductivity $(<0.5 \mathrm{~W} / \mathrm{m} \mathrm{K})$. The maximum removable heat from the containment is about $7.5 \mathrm{MW}$.

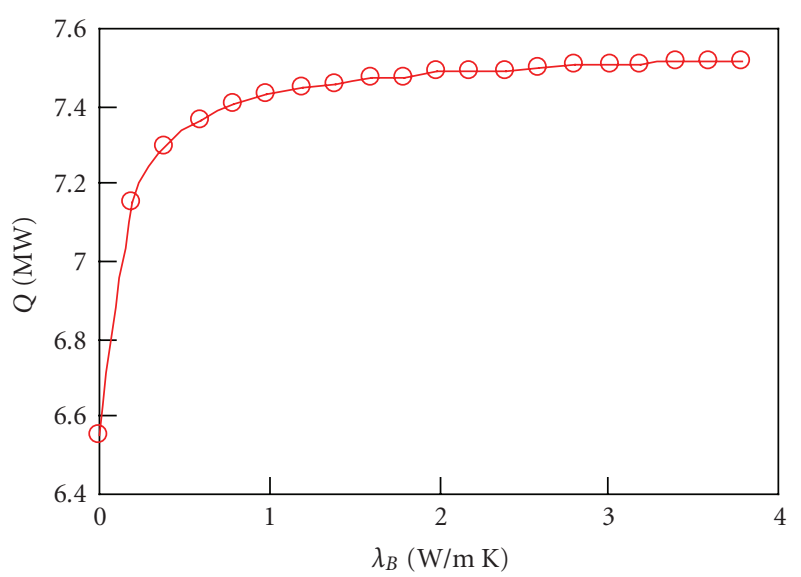

Figure 7: Effect of thermal conductivity of the buffer plate $\lambda_{B}$ on heat transfer capability $Q$.

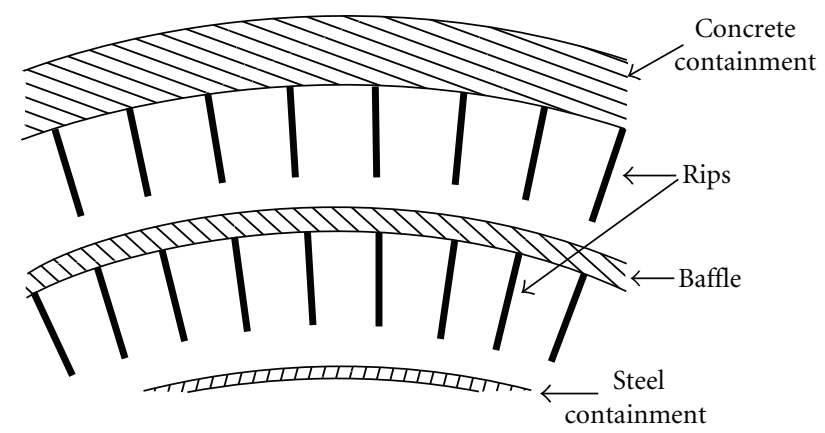

FIGURE 8: Improvement for heat removal using ribs [14].

According to the thermal power of AP1000 (3400 MWth) and the simplified decay heat curve

$$
Q(t)=0.062 \cdot Q_{0} \cdot t^{-0.2} .
$$

Here $Q(t)$ is the time dependent decay heat power, $Q_{0}$ the reactor thermal power before shutdown, and $t$ time in seconds. The decay heat in an AP1000 goes down to the level 7.5 MW 40 days after the shutdown of the reactor. Obviously, this passive system is insufficient to remove decay heat and needs improvement, especially for the Chinese GEN-III PWR with a much larger thermal power. Therefore, various improvement suggestions are proposed. One of the possibilities to enhance the heat removal is to introduce ribs, as shown in Figure 8. Detailed analysis shows that with this new structure, an increase of $15 \%$ in heat removal capability can be achieved [14].

3.2. Ex-Vessel Cooling of In-Vessel Retention. During the transient phase of severe accident (SA) progression, integrity of the reactor pressure vessel (RPV) lower head is threatened by a wide spectrum of phenomena, for example, various melt relocation scenarios, potential steam explosion, jet impingement, and so forth. A limiting case and strategy in late phase of SA is maintenance of lower head integrity through external cooling of the lower head of reactor 


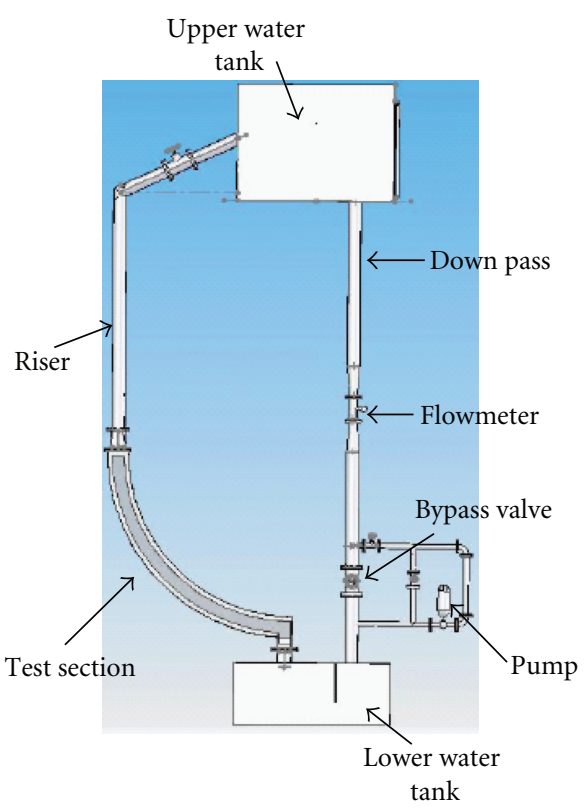

(a) Scheme of the REPEC facility

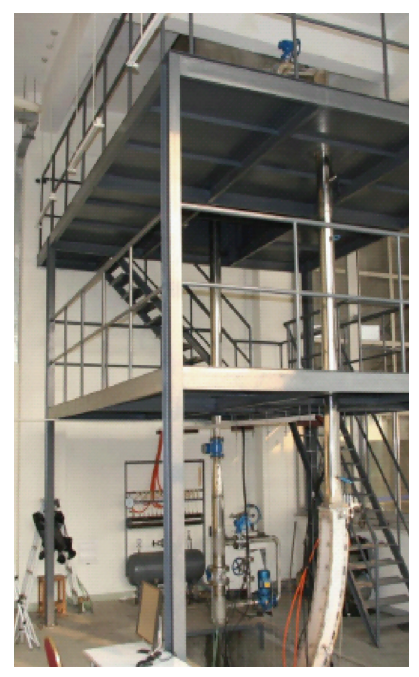

(b) Photograph of the REPEC

FIgUre 9: Test facility REPEC for ERVC-IVR.

pressure vessel to reach the in-vessel retention of molten pool (IVR-ERVC).

The IVR-ERVC concept was first investigated and explored for the Loviisa pressurized water reactor (PWR) in Finland. It was accepted as the major accident management measure by the Finnish regulatory agency. In the USA, the design of the advanced passive reactor AP600 and AP1000 employs reactor ex-vessel flooding as an accident management scheme [2]. The safety strategy of AP1000 is to keep RPV intact at any conditions, including severe accident core melt conditions. There is no core catch outside RPV. Late on, IVR-ERVC was also proposed for other PWRs and BWRs such as Korean APR-1400 [15] and German SWR1000 [16].

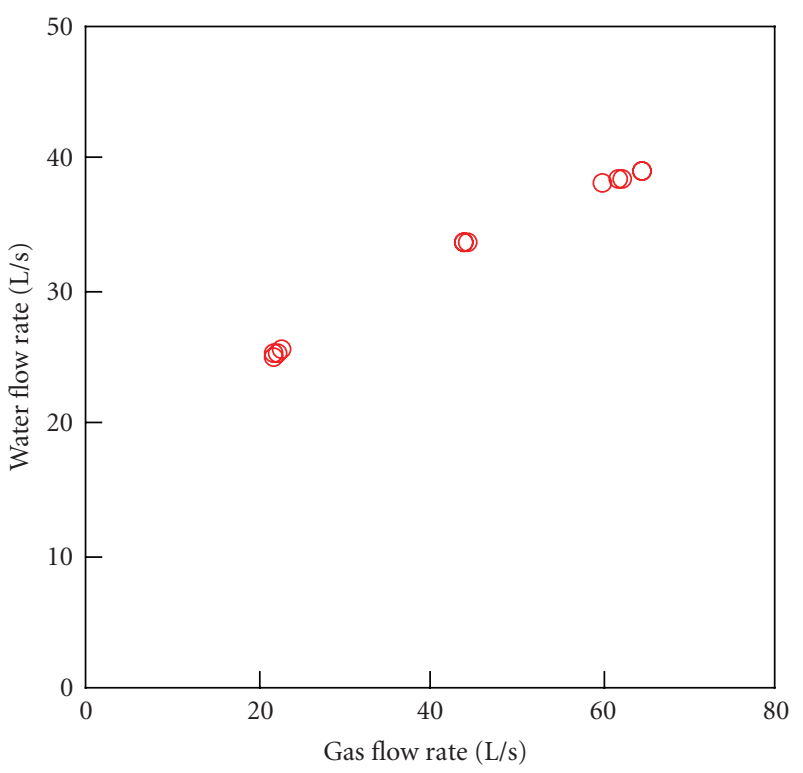

FIGURE 10: Dependence of induced waters flow rate versus injected air flow rate.

For the past years, the thermal loading imposed by the core melt on the reactor pressure vessel (RPV) lower head has been the major focus of the above studies. The objectives were to determine, (a) whether the imposed heat flux exceeds the heat removal capability $(\mathrm{CHF})$ on the external surface, (b) the potential for melting of the vessel wall under the thermal loading from the molten pool, and (c) the pressure bearing capability of the vessel wall held at high temperature inside and low temperature outside.

In China, SNERDI has adopted IVR-ERVC concept in the design of Chashima-2 $300 \mathrm{MW}$ NPP. Engineering investigation has been conducted during the design period. Furthermore, China Guangdong Nuclear Power Corporation (CGNPC) is also considering to apply IVR-ERVC strategy in the CPR1000 design.

For extending the reactor power of AP1000 to higher level, for example, $1400 \mathrm{MW}$, the feasibility of the passive IVR-ERVC concept becomes one of the bottlenecking factors and attracts extremely strong attention of the Chinese nuclear community. Both experimental and theoretical studies were initiated at SJTU two years ago, in collaboration with SNERDI and CGNPC. Figure 9 shows schematically the test facility REPEC built at SJTU. The experimental study consists of three phases, as summarized as follows.

(i) Phase I. Cold tests: in this phase air is used to simulate steam. The main purpose is to study two-phase flow characteristics in the test section and the natural circulation capability of the passive system.

(ii) Phase II. Hot tests: the test section is electrically heated to produce steam. The main purpose of this test phase is to study two-phase flow and heat transfer behavior, including critical heat flux, in the gap and on the surface of the reactor pressure vessel. Stability 
of the natural circulation is also one of the main phenomena under consideration.

(iii) Phase III. Small-scale three-dimensional ERVC assessment test and scaling law.

The cold tests have been started in October 2008. Figure 10 shows one preliminary result indicating the total water flow rate in dependence on the injected air flow rate under natural circulation conditions. The higher the air mass flow rate, the larger the induced water flow rate. These test data can be used for the validation of system analysis codes.

\section{Summary}

Development of environment friendly energy supplies becomes a crucial issue in the future Chinese economy. Due to the well-known limitation in renewable energy and hydro-power, nuclear power is considered as a safe, clean, sustainable, and economic energy source. Recently, the Chinese government issued an ambitious program of midterm and long-term nuclear power development. Nuclear safety was well recognized having the top priority in the nuclear power development. For the near-term and mediumterm, the Chinese nuclear community decided for advanced pressurized water reactors with an extensive usage of passive safety systems.

As the reference concept of the advanced PWR of GENIII, China introduces the AP1000 NPP of Westinghouse and is organizing the corresponding technology transfer. In the other side large efforts are made to accelerate the self-reliance process of the GEN-III PWR technology. The Chinese government has issued a large national program to develop self-reliance technology of "Chinese large-scale advanced PWR nuclear power plant". A central organization, the State Nuclear Power Technology Cooperation, was established, to coordinate the nationwide activities.

Nowadays, research activities on passive safety systems have been initiated at various institutions, such as Shanghai Jiao Tong University (SJTU), Shanghai Nuclear Engineering Research and Design Institute (SNERDI) and, Nuclear Power Institute of China (NPIC). A rapid expansion of R\&D activities in this field is expected. Considering the global importance of nuclear safety and the existing experience worldwide in nuclear safety research, especially related to passive safety systems, an enhanced exchange and collaboration with international nuclear community is highly desired. The International Workshop on Passive Safety Systems in Advanced PWRs (IPASS'80), which was held on April 28-30, 2008 at SJTU, is an important step toward this direction. Continuation of this kind of efforts by national and international nuclear communities will significantly contribute to the progress of nuclear safety research in China and to a sustainable nuclear power development worldwide.

\section{References}

[1] Nuclear Power Medium and Long-Term Program (20052020), "National Development and Reform Commission
(PRC)," 2007.

[2] W. E. Cummins, M. M. Corletti, and T. L. Schulz, "Westinghouse AP1000 advanced passive plant," in Proceedings of International Congress on Advances in Nuclear Power Plants (ICAPP '03), Cordoba, Spain, May 2003.

[3] J. Czech, F. Bouteille, and G. Hudson, "EPR: an advanced evolutionary design," in Proceedings of the International Congress on Advances in Nuclear Power Plants (ICAPP '04), pp. 133-141, Pittsburgh, Pa, USA, June 2004, paper 4198.

[4] National Medium and Long-Term Science and Technology Plan (2006-2020), "The State Council of the People's Republic of China," 2006.

[5] Y. Ouyang, "Development strategy and process of world nuclear power states and nuclear power development in China," China Nuclear Power, vol. 1, no. 2, pp. 118-125, 2008.

[6] P. Bo and Z. Tan, "Passive safety system design for AC-600," Nuclear Power Engineering, vol. 10, no. 5, 1989 (Chinese).

[7] C. Lu, Z. Qin, W. H. Niu, and S. X. Luo, "Passive safety systems research and design of LIPR," in Proceedings of International Workshop on Passive Safety Systems in Advanced Chinese PWRs, Shanghai, China, April 2008, paper D02.

[8] J. R. Wang, "Boron injection system in a nuclear heating reactor," in Proceedings of International Workshop on Passive Safety Systems in Advanced Chinese PWRs, Shanghai, China, April 2008, paper D06.

[9] M. D. Carelli, et al., "IRIS reactor design overview and status update," in Proceedings of the International Congress on Advances in Nuclear Power Plants (ICAPP '05), Seoul, Korea, May 2005, paper 5095.

[10] K. M. Cao, "Analysis of two-phase natural flow through the flow path between RPV and insulation of AP1000 passive plant with RELAP5 Code," in Proceedings of International Workshop on Passive Safety Systems in Advanced Chinese PWRs, Shanghai, China, April 2008, paper C03.

[11] Y. H. Yang, "Research activities on nuclear passive safety at SJTU," in Proceedings of International Workshop on Passive Safety Systems in Advanced Chinese PWRs, Shanghai, China, April 2008, paper S02.

[12] W. B. Zhu, "Experimental research on passive residual heat removal system of Chinese advanced PWR," in Proceedings of International Workshop on Passive Safety Systems in Advanced PWRs, Shanghai, China, April 2008, paper E04.

[13] S. S. Tan, G. J. Leng, H. J. Neitzel, H. Schmidt, and X. Cheng, "Investigations on the passive containment cooling system of an advanced Chinese PWR," Wissenschaftliche Berichte, FZKA-6622, December 2001.

[14] W. S. Cui, J. X. Liu, and X. Cheng, "Performance analysis of passive safety containment cooling system," in Annual Meeting of National Key Laboratory of Bubble Physics \& Natural Circulation, Chengdu, China, 2006.

[15] J. L. Rempe, D. L. Knudson, K. G. Condie, K. Y. Suh, F.-B. Cheung, and S.-B. Kim, "Corium retention for high power reactors by an in-vessel core catcher in combination with External Reactor Vessel Cooling," Nuclear Engineering and Design, vol. 230, no. 1-3, pp. 293-309, 2004.

[16] Z. V. Stosic, W. Brettschuh, and U. Stoll, "Boiling water reactor with innovative safety concept: the Generation III+ SWR1000," Nuclear Engineering and Design, vol. 238, no. 8, pp. 1863-1901, 2008. 

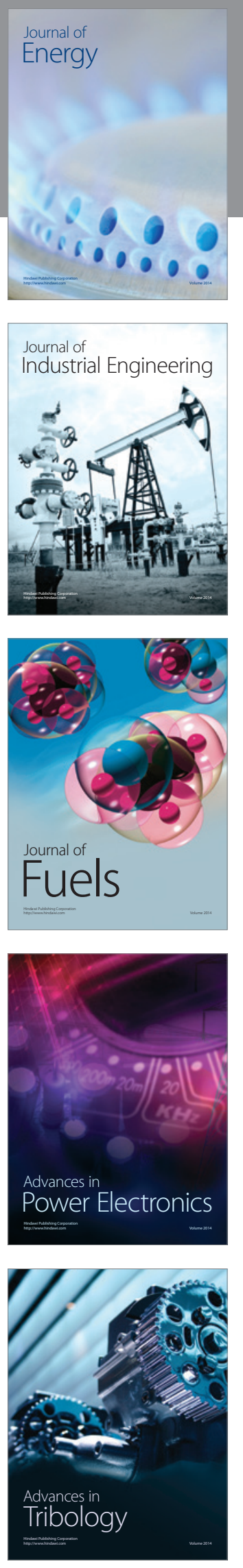
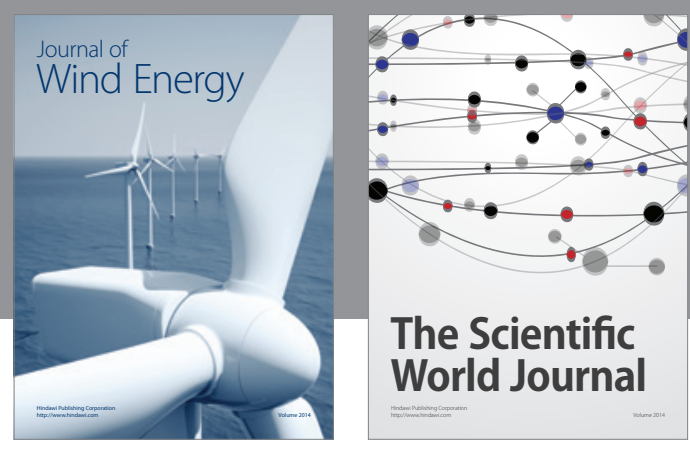

The Scientific World Journal

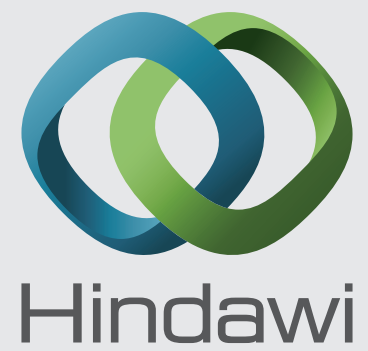

Submit your manuscripts at http://www.hindawi.com
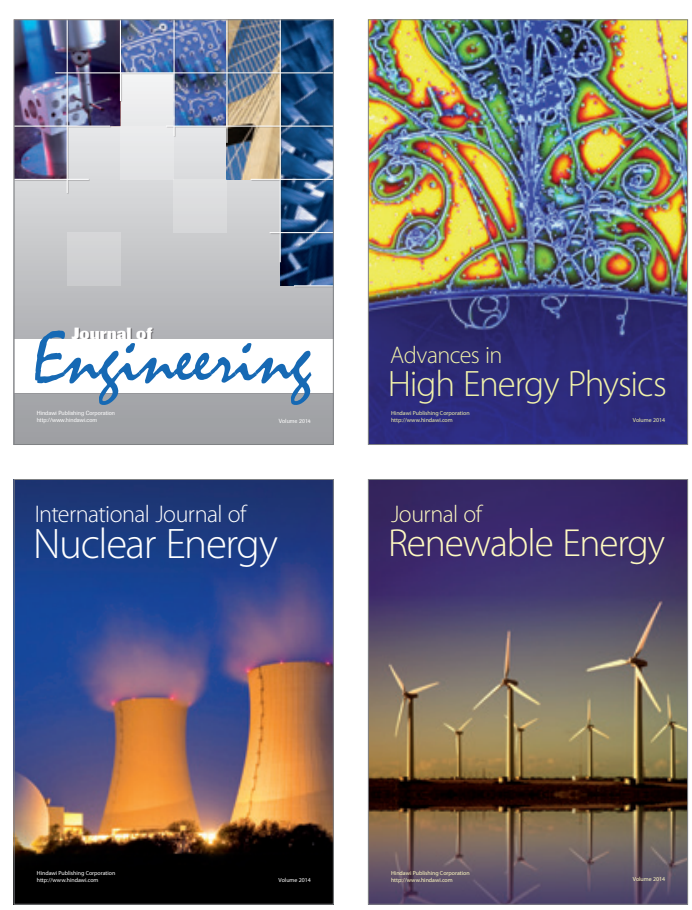

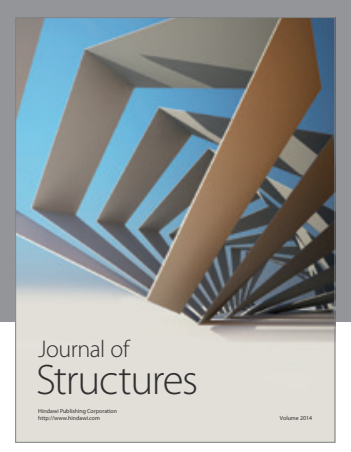

Rotating
Mechinery
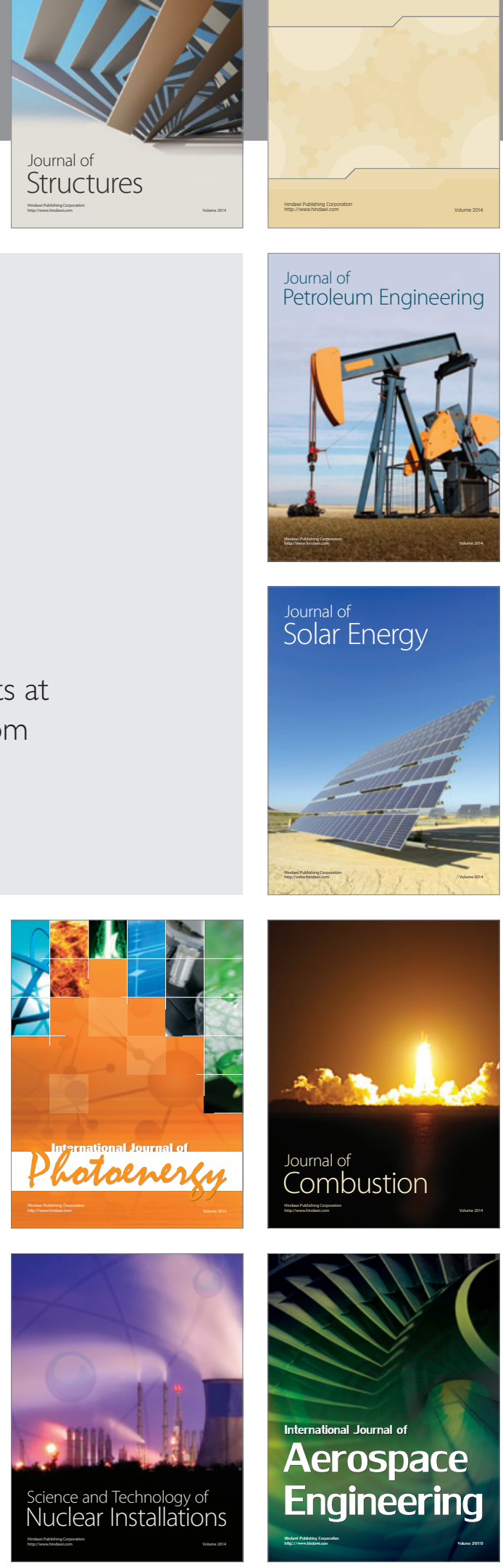